\title{
VISCERAL LEISHMANIASIS IN GREECE: UNDER-REPORTED OR UNDER-ESTIMATED?
}

A. Pana1, A. Barmpakou1, M. Berikopoulou2, P. Panas3, K. Plagiannakou1, I. Panagiotou1. 1 General Hospital of Lakonia- Nursing Unit of Sparta, Pediatrics, Sparta, Greece.

2 General Hospital of Lakonia- Nursing Unit of Sparta- Health Center of Gytheion, Pediatrics, Sparta, Greece. 3University Hospital of Patras 'Panagia i Voithia', Obstetrics- Gynecology, Patras, Greece.

\section{Background}

Visceral leishmaniasis (VL) has been characterized a neglected tropical disease, endemic in over 98 countries worldwide. Greece is considered an endemic country, in nearly all geographical areas, with visceral leishmaniasis being the predominant form. L.infantum is the species responsible for the disease while the vectors transferring the parasite are Phlebotomine sandflies (P.neglectus, P.tobbi, P.perfiliewi). Dogs are considered the main reservoir hosts and humans are basically accidental hosts. Various studies have shown high proportions of seropositivity in dogs in various areas of the country $(20-24 \%)$.

Leishmaniasis is a mandatory notifiable disease in Greece. During the years 2004-2014, 606 new cases of VL were reported. The annual incidence of $V L$ ranged from $0,27-0,78$ new cases per 100.000 population (median annual incidence 0,51 ). Lakonia is a Regional Unit in Peloponesse, South Greece with a population of 89.138 residents. The annual incidence of $\mathrm{VL}$ in the area is estimated between $0,71-1,00$ per 100.000 population.

In the following map of Greece, Lakonia perfecture pointed by the arrow, is concidered endemic for VL (HCDCP data 2004-2014).
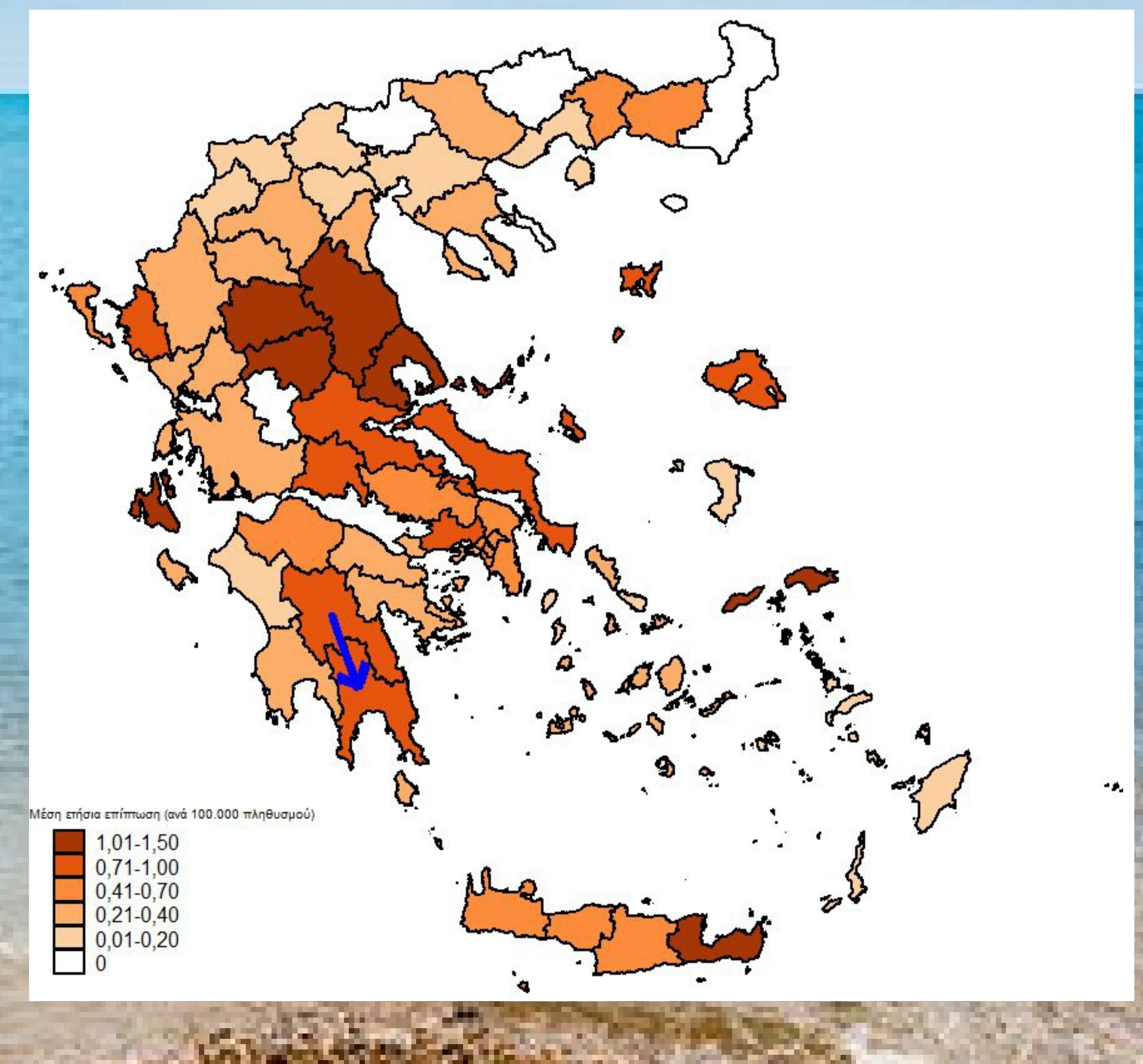


\section{VISCERAL LEISHMANIASIS IN GREECE: UNDER-REPORTED OR UNDER-ESTIMATED?}

A. Pana1, A. Barmpakou1, M. Berikopoulou2, P. Panas3, K. Plagiannakou1, I. Panagiotou1.

1 General Hospital of Lakonia- Nursing Unit of Sparta, Pediatrics, Sparta, Greece.

2General Hospital of Lakonia- Nursing Unit of Sparta- Health Center of Gytheion, Pediatrics, Sparta, Greece. 3University Hospital of Patras 'Panagia i Voithia', Obstetrics- Gynecology, Patras, Greece

\section{Case Presentation Summary}

During 2017, we report four new cases of VL diagnosed in the General Hospital of Lakonia- Nursing Unit of Sparta. The three new cases were children aged 3,5 and 8 years old respectively. The fourth case was a 42-year-old male. The appearance of the cases is shown in the image below. All four cases presented with fever, hepatosplenomegaly, pancytopenia and positive rK39 antigen. The diagnosis was sealed by demonstration of the parasites in bone marrow sample. The laboratory findings of each case are demonstrated in the following table.

All four patients were treated with liposomal amphotericin B with excellent response and no relapses. The three children were reassessed within one month after release and their laboratory exams were normal.

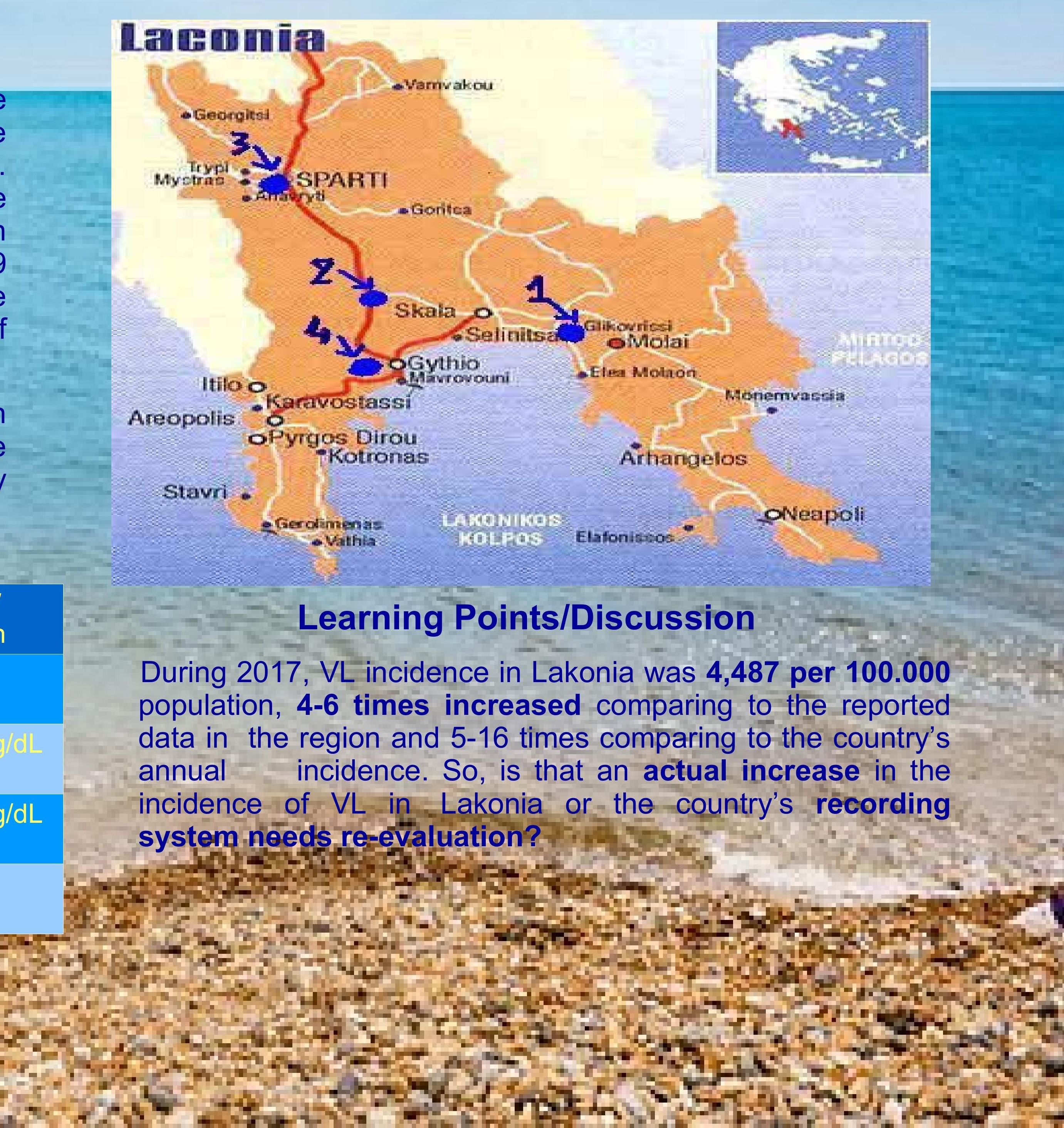

